\title{
Assessment of spatial coupling coordination in the Three Gorges reservoir area- Taking Badong County as an example
}

\author{
Li Guiyuan ${ }^{1, *}$, He Zhao $^{2}$ \\ ${ }^{1}$ Hubei University of Technology, Wuhan, Hubei \\ ${ }^{2}$ China Three gorges university, Yichang, Hubei
}

\begin{abstract}
The special geographical location leads to the mutual restriction of urban spatial natural resources, material space and economy and society in the Three Gorges reservoir area, which threatens the spatial security of the towns. Based on the characteristics of multidimensional coupling between systems, this study uses Badong County as an example to evaluate the trend of coupling coordination between natural resources-material space-economic society and society by using the coupling coordination model. The results show that although the coupling degree between systems in Badong County is as high as 0.9546 and the degree of interaction is very strong, the degree of coupling coordination is only a moderate imbalance development type. Therefore, it is an urgent problem to improve the level of coupling and coordination between systems and ensure the safety of urban space.
\end{abstract}

\section{Introduction}

"Coupling" originated in physics, with the continuous extension and deepening of the concept, its concept has gradually penetrated into the field of research in all directions ${ }^{123}$. As far as system coupling is concerned, foreign research originated from the exploration of human-terrestrial relationship theory at the end of the 20th century, and the concept of social-ecosystem coupling was put forward for the first time ${ }^{45}$. Based on this, experts in various fields of academic circles in China also focus on the human-natural system $^{67}$, urbanization-ecological environment system dual coupling ${ }^{89}$ and ecological-economic-social system multidimensional coupling and other aspects of in-depth discussion ${ }^{1011}$

The Three Gorges reservoir area is located in the hinterland of the Yangtze River basin, because the special geographical location makes the natural resources-material space-economic and social systems restrict each other, coupling and coordination level is low, so the geological disasters are frequent, the ecological environment is fragile and sensitive, and the safety of towns is threatened ${ }^{12}$. With the rapid urbanization process, more agricultural population to the town, the urban population climbs, resulting in a serious problem of human-land contradictions ${ }^{13}$. At the same time, there is a contradiction between the scale of material space facilities and the growing living needs of the residents, which limits the prosperity and development of the economy and society ${ }^{14}$. Therefore, based on the characteristics of multidimensional coupling between systems, this paper uses the coupling coordination model to evaluate the level of coupling coordination and evolution trend in Badong County in 2010, 2015 and 2020. Based on this result, the targeted giving strategy enhances the level of spatial coupling coordination in Badong County in order to ensure the safety of urban space.

\section{Overview of the study region}

\subsection{Natural Resources Overview}

Badong County is located in the north-east of the Hmong Autonomous Prefecture of the Guenshi Tu family, which is a border county in western Hubei Province, located at 110 degrees $04-110$ degrees 32 degrees east longitude and 30 degrees 13 degrees north latitude and 31 degrees 28 degrees north latitude. The county's terrain northsouth narrow shape like "dumbbell", the north-south maximum longitudinal $129 \mathrm{~km}$, the east-west minimum cross-section $10.3 \mathrm{~km}$, the tectonic pattern is complex, west high east low, north-south ups and downs, rugged surface, is a typical karst landscape, the average elevation of $1089.3 \mathrm{~m}$.

Badong County is warm and rainy, wet, hot and foggy, with clear seasons. Sufficient water resources, warm, humid and rainy, the average annual precipitation of 700 to $1400 \mathrm{~mm}$, mainly concentrated in April to October, accounting for $86.8 \%$ of the year, is a typical subtropical monsoon climate.

*1gy@hbut.edu.cn,616105695@qq.com 


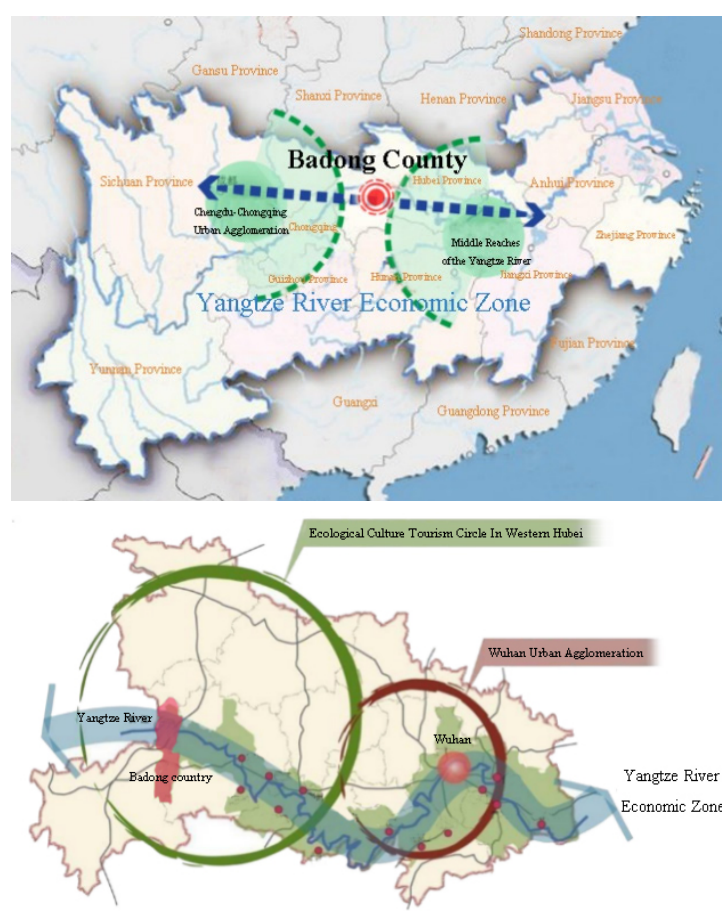

Fig.1 The geographical location of Badong County

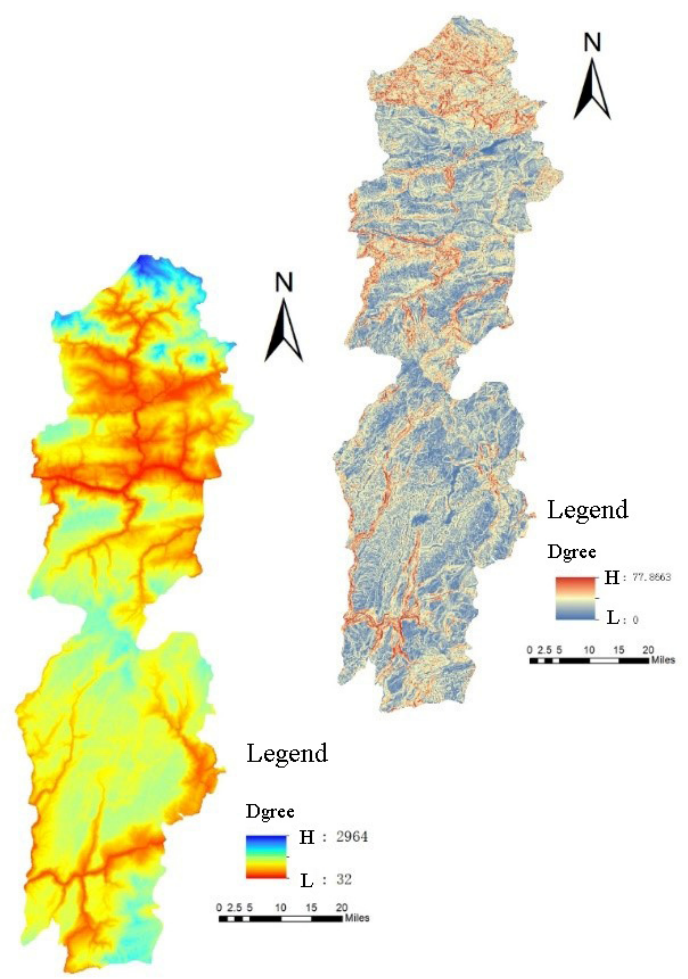

Fig.2 Map of the terrain slope of Badong County

\subsection{Physical space profile}

There are 12 townships in Badong County, such as sports service centers, sports and fitness projects, chemical rooms and other public service facilities. The county has 499 medical and health institutions, including 2 countylevel hospitals, 1 disease control agency, 1 maternal and child health care institution, 1 health supervision agency, 12 township hospitals and a number of central health rooms and village health rooms, with 1161 active health personnel, including 1048 professional and technical personnel. The county has educational facilities including 3 high schools, 1 vocational high school, 1 special education school, 19 junior secondary schools and a number of primary schools, kindergartens and so on. Educational facilities are distributed in various townships, resources are more balanced, basically can meet the primary education needs of the corresponding population.

There are 18 reservoirs in Badong County, with a total storage capacity of 460,821.39 million $\mathrm{m} 3$, of which 1 is a large reservoir and 17 are small reservoirs. The total design irrigation area of $371,000 \mathrm{mu}$, the total design of the annual water supply of 11.33 million $\mathrm{m} 3$. The townships only have drainage pipes in the central urban areas, discharged to sewage treatment plants, the rest of the townships do not have systematic drainage

planning, along the two sides of the road drainage ditches scattered into the town's river network water body, so it caused great damage to the ecological environment.

\subsection{Economic and Social Overview}

In 2010, Badong County achieved a regional GDP of 4,934 million yuan, of which the primary industry completed the value added of 1.290 billion yuan, the secondary industry completed the value added of 1.873 billion yuan, and the tertiary industry completed the value added of 1.771 billion yuan. The contribution of the tertiary industry to GDP reached $38.0 \%$, respectively, driving GDP growth by 6.1 percentage points. In 2015, Badong County achieved a regional GDP of 8.88 billion yuan, of which the primary industry completed the value added of 1.73 billion yuan, the value added of the secondary industry 3.67 billion yuan, the value added of the tertiary industry 3.48 billion yuan. At the beginning of 2019 (as the 2020 statistics have not yet been presented, this paper selects the 2019 data), the county completed the regional GDP of 12.746 billion yuan, of which the value added of the primary industry 2.265 billion yuan, the value added of the secondary industry 3.149 billion yuan, the value added of the tertiary industry 7.332 billion yuan.

Tab.1 Summary of economic data of Badong County

\begin{tabular}{lllll}
\hline Year & $\begin{array}{c}\text { GDP } \\
\text { (Hundred } \\
\text { million })\end{array}$ & $\begin{array}{c}\text { The first industry } \\
\text { (Hundred million })\end{array}$ & $\begin{array}{c}\text { The second industry } \\
\text { (Hundred million) }\end{array}$ & $\begin{array}{c}\text { The third industry } \\
\text { (Hundred million) }\end{array}$ \\
\hline
\end{tabular}




\begin{tabular}{ccccccccc}
\cline { 2 - 9 } & gross & growth & gross & growth & gross & growth & gross & growth \\
\hline 2010 & 49.34 & $14.8 \%$ & 12.90 & $3.2 \%$ & 18.73 & $21.6 \%$ & 17.71 & $17 \%$ \\
2015 & 88.8 & $9.0 \%$ & 17.3 & $5.3 \%$ & 36.7 & $8.4 \%$ & 34.8 & $11.7 \%$ \\
2020 & 127.46 & $4.9 \%$ & 22.65 & $3.3 \%$ & 31.49 & $1.3 \%$ & 73.32 & $8.6 \%$ \\
\hline
\end{tabular}

\section{Construction of coupling coordination degree evaluation model}

\subsection{The establishment of index weight}

\subsubsection{Data standardization}

Since the units of measurement of the indicators are not uniform, in order to eliminate the influence of the scale and converge the direction of the effect of all indicators on the evaluation objectives, the data should be standardized, that is, the absolute value of the indicators into relative values, the indicators of different quality homogenization. In this paper, the original index data is standardized by the deviation standardization method (min-max method). Here's how:

(1)Forward index processing formula:

$$
y_{i j}=\frac{x_{i j}-\operatorname{Min}\left(x_{j}\right)}{\operatorname{Max}\left(x_{j}\right)-\operatorname{Min}\left(x_{j}\right)}
$$

(2) Negative index processing formula:

$$
y_{i j}=\frac{\operatorname{Min}\left(x_{j}\right)-x_{i j}}{\operatorname{Max}\left(x_{j}\right)-\operatorname{Min}\left(x_{j}\right)}
$$

Among them, yij is the standardized value of each indicator; $\mathrm{Xij}$ is the first sample (i-1, 2,3... n) J indicator $(\mathrm{j}-1,2,3 \ldots \mathrm{m})$ raw data; $\min (\mathrm{xj})$ is the minimum value for all samples and max (xj) for all samples.

\subsubsection{Weight definition}

In this paper, entropy is used to determine the weight of the indicator. Entropy is a measure of the degree of information disorder. When the greater the degree of dispersion of an indicator, reflecting the large amount of effective information provided by the series, the greater its entropy, the greater the impact of the indicator on the comprehensive evaluation, which is reflected in a higher weight value; Conversely, the smaller the degree of dispersion, the greater the entropy and the lower the weight value. This method has been widely used in the quantitative evaluation of economics and economic geography.

(1) Entropy value Ej of the $\mathrm{j}$ index is calculated:

$$
e_{j}=-\frac{\left[\sum_{i=1}^{m} P_{i j} \ln \left(P_{i j}\right)\right]}{\ln m}
$$

(2) Calculate the difference coefficient gj of the $\mathrm{j}$ index. The larger the difference coefficient is, the better the evaluation effect is:

$$
g_{j}=1-e_{j}
$$

(3) Calculate the weight of the $\mathrm{j}$ index:

$$
w_{j}=\frac{g_{j}}{\sum_{j}^{n} g_{j}}
$$

\subsection{Construction of coupling coordination evaluation system}

Based on the qualitative analysis of the general situation of the systems in Badong County and the summary of related studies, this paper constructs a coordinated

\begin{tabular}{|c|c|c|c|c|c|}
\hline & $\begin{array}{l}\text { The first } \\
\text { indicators }\end{array}$ & $\begin{array}{c}\text { Index } \\
\text { weight }\end{array}$ & The secondary indicators & $\begin{array}{c}\text { Index } \\
\text { properties }\end{array}$ & Index weight \\
\hline & & & Depth of reservoir water level & - & 0.0447 \\
\hline & & & Number of damage points & - & 0.0524 \\
\hline & & & Mean altitude & - & 0.0368 \\
\hline evaluatio & $\begin{array}{c}\text { Natural } \\
\text { resources }\end{array}$ & 0.3610 & Total water resources & + & 0.0250 \\
\hline $\mathrm{n}$ & & & Forest coverage & + & 0.0218 \\
\hline \multirow{2}{*}{ index } & & & Total arable land resources & + & 0.0200 \\
\hline & & & Cultivated area in common use & + & 0.0236 \\
\hline
\end{tabular}
assessment system of spatial natural resources-material space-economic and social coupling in Badong County, as shown in the following table:

Tab.2 Coordinated evaluation system of urban space coupling 


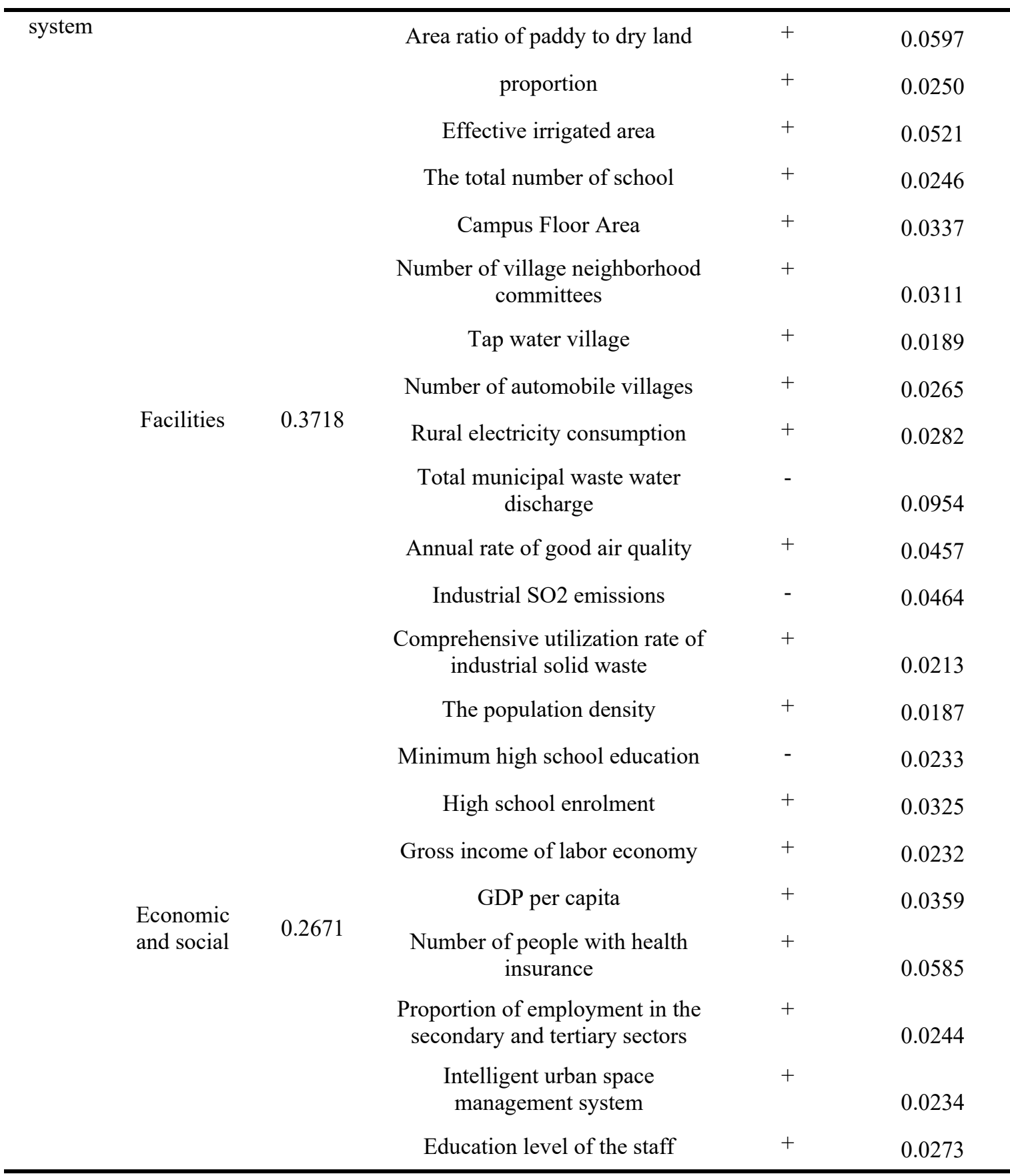

\subsection{Calculation method of coupling coordination degree evaluation}

"Coupling degree" is to describe the interrelationship between the system and the system elements and the degree of influence, the calculation results can only be clear natural resources - material space - economic society and society whether there is an interaction between the relationship and the extent of the interaction, and can not accurately express whether such interaction reached the level of coordinated development. The "coupling coordination model" can measure the benign development level of the interaction relationship between the systems, and the higher the value, the higher the coordinated development level of the systems between the complex giant systems, so as to present a more stable and safe urban space and achieve sustainable development. Because the meta-difference between system or system elements will be applied to different calculation methods and models, this study is intended to calculate the coupling coordination of the three systems of natural resource-material space-economic society in Badong County, so this paper refers to the triple system coupling model. First, set the coordination deviation coefficient of the ternary system as:

$$
C=\left[U_{1} * U_{2} * U_{3} /\left(\frac{U_{1}}{3}+\frac{U_{2}}{3}+\frac{U_{3}}{3}\right)\right]^{1 / 3}
$$

Among them, U1, U2, U3 represent the naturalmaterial space-economic society and society three systems comprehensive evaluation function, $\mathrm{C}$ is the coupling degree, its value is between the s0,1, according to the coupling model research summary, the coupling degree is divided into six levels, the specific coupling affects the relationship type as follows: 
Tab.3 List of influence types and value range of coupling degree

\begin{tabular}{cc}
\hline the type of relationship & The range of C \\
\hline disorderly development & $\mathrm{C}=0$ \\
Low level coupling phase & $\mathrm{C} \in(0,0.3]$ \\
Antagonism phase & $\mathrm{C} \in(0.3,0.5]$ \\
Running-in stage & $\mathrm{C} \in(0.5,0.8]$ \\
Phase of high level coupling & $\mathrm{C} \in(0.8,1]$ \\
\hline this paper introduces the system coupling & $T=a * U_{1}+b * U_{2}+c * U_{31}$
\end{tabular}
coordination model from the relevant influence, coordinated development level two aspects to better simulate the Badong County urban space complex giant system natural resources - material space - economic and social three systems of the time coupling coordination degree, coupling coordination degree model is as follows:

$$
D=\sqrt{C} * \sqrt{T}
$$

Among them: $\mathrm{D}$ is the coupling coordination between the three systems; $\mathrm{C}$ is coupling; $\mathrm{T}$ is the composite coordination index; $\mathrm{a}, \mathrm{b}, \mathrm{c}$ is the pending coefficient, i.e. the three system weight values calculated on the basis of entropy rights. Through the research summary of the coupling coordination model, the coupling coordination degree is divided into four levels, as shown in the following table:

Tab.4 List of coupling coordination types and value ranges

\begin{tabular}{|c|c|c|c|}
\hline $\begin{array}{l}\text { The coupling } \\
\text { coordination phase }\end{array}$ & $\begin{array}{c}\text { D-value } \\
\text { category division }\end{array}$ & $\begin{array}{c}\text { D-value } \\
\text { small class division }\end{array}$ & Type \\
\hline \multirow{4}{*}{$\begin{array}{l}\text { Low level } \\
\text { coordinated coupling }\end{array}$} & \multirow{4}{*}{$\mathrm{D} \in(0,0.4]$} & $0-0.1$ & $\begin{array}{l}\text { Extremely maladjusted } \\
\text { development class }\end{array}$ \\
\hline & & $0.1-0.2$ & Severe disorders of development \\
\hline & & $0.2-0.3$ & Moderate disorder development \\
\hline & & $0.3-0.4$ & Mild disorder development \\
\hline $\begin{array}{l}\text { Medium-level } \\
\text { coordinated coupling }\end{array}$ & $\mathrm{D} \in(0.4,0.5]$ & $0.4-0.5$ & $\begin{array}{c}\text { Developmental classes at risk of } \\
\text { disorder }\end{array}$ \\
\hline \multirow{3}{*}{$\begin{array}{l}\text { High level of } \\
\text { coordinated coupling }\end{array}$} & \multirow{3}{*}{$\mathrm{D} \in(0.5,0.8]$} & $0.5-0.6$ & $\begin{array}{c}\text { Barely coordinated development } \\
\text { class }\end{array}$ \\
\hline & & $0.6-0.7$ & $\begin{array}{c}\text { Primary coordinated development } \\
\text { category }\end{array}$ \\
\hline & & $0.7-0.8$ & $\begin{array}{l}\text { Intermediate coordinated } \\
\text { development class }\end{array}$ \\
\hline \multirow{2}{*}{$\begin{array}{l}\text { Extremely high } \\
\text { levels of coordinated } \\
\text { coupling }\end{array}$} & \multirow{2}{*}{$\mathrm{C} \in(0.8,1]$} & $0.8-0.9$ & $\begin{array}{c}\text { Good coordinated development } \\
\text { class }\end{array}$ \\
\hline & & $0.9-1.0$ & $\begin{array}{l}\text { Quality and coordinated } \\
\text { development }\end{array}$ \\
\hline
\end{tabular}

When $\mathrm{D}<0.5$, the system is in the stage of low level coordination coupling and medium level coordination coupling, which belongs to the type of misalignment development. The lower the value, the higher the level of misalignment, and vice versa. When $\mathrm{D}>0.5$, the system is in the stage of high level coordination coupling and extremely high level coordination coupling, which belongs to the type of coordination development. The higher the value, the better the coordination level, and vice versa.

\section{Result analysis}

\subsection{Coupling degree analysis}

Based on the evaluation index system of natural resource-material space-economic and social coupling coordination of the complex giant system of urban space in Badong County, this paper calculates the coupling value $\mathrm{C}$ for 2010, 2015 and 2020 according to the 4.3.3 formula, as shown in the table below: 
Tab.5 Calculation results of coupling degree (C) Badong County

\begin{tabular}{ccc}
\hline Year & Coupling degree C value & type of relationship \\
\hline 2010 & 0.8682 & Phase of high level coupling \\
2015 & 0.9383 & Phase of high level coupling \\
2020 & 0.9321 & Phase of high level coupling \\
\hline
\end{tabular}

According to the calculation results and the criteria listed above, it can be seen that the coupling degree of urban spatial natural resources-material space-economic society and society of the complex mega-system in Badong County has generally shown the stage development trend of high-level coupling from 2010 to 2020. In 2015, the coupling degree increased significantly from 2010 , by 8.07 percentage points; This was followed by a slight decrease in coupling in 2020 from 2015, by 0.66 percentage points. Although coupling values have fluctuated significantly over a decade slightly, they are still above the magnitude of the highlevel coupling phase and do not change much. Therefore, the degree of coupling value shows that: Badong County urban spatial natural resources - material space economic and social interaction between the three systems, the relationship between the more and more strong, the relationship is very close, showing a highly coupled state, coupling change trend as shown in the following chart:

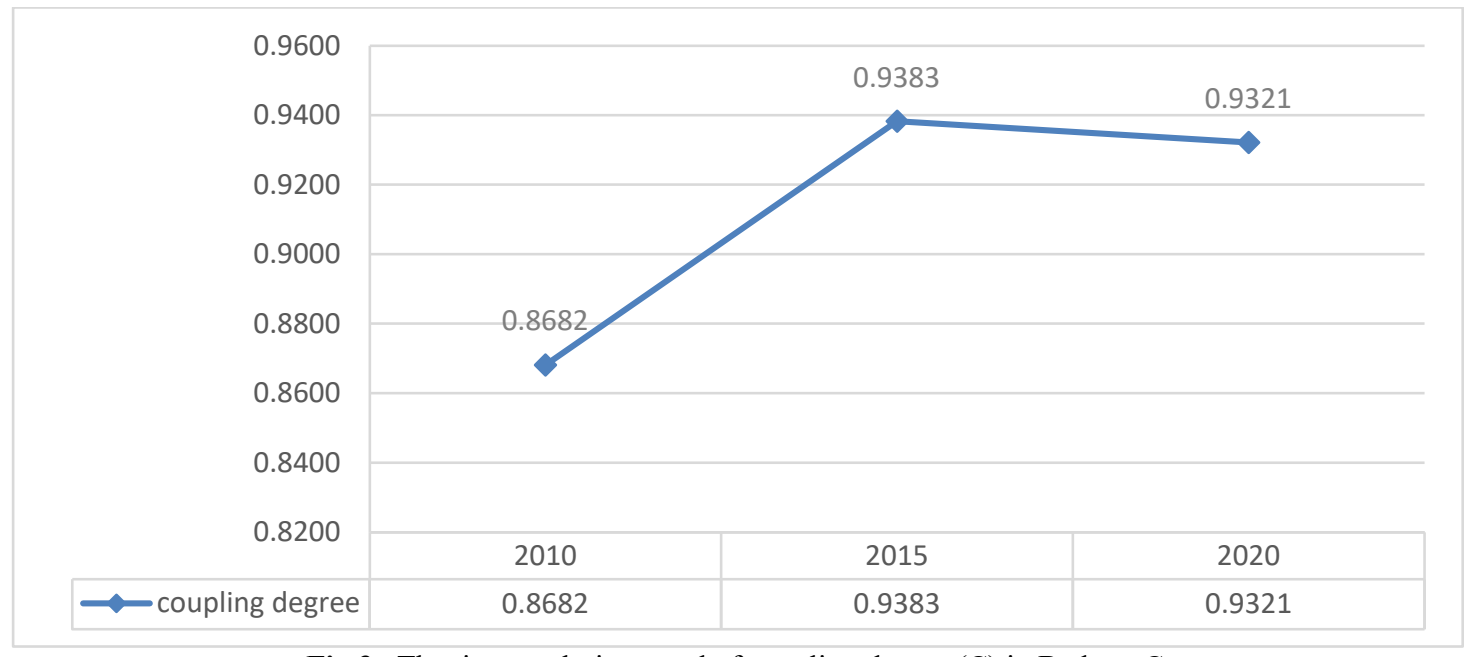

Fig.3 The time evolution trend of coupling degree (C) in Badong County

\subsection{Coupling coordination degree result analysis}

Based on the coupling calculation and change trend of the natural resource-material space-economic society and society in the towns of Badong County in 2010, 2015 and 2020, and then based on the coupling coordination model and calculation formula, the coupling coordination degree of the urban space in Badong County in 2010, 2015 and 2020 can be used to analyze the trend of the coordinated development of the coupling degree between the three systems of natural resource-material spaceeconomic society. The results are shown in the table below:

Tab.6 Calculation results of coupling coordination degree (D) in Badong County

\begin{tabular}{cccc}
\hline Year & $\mathrm{T}$ & $\begin{array}{c}\text { D-value of coupling } \\
\text { coordination degree }\end{array}$ & type of relationship \\
\hline 2010 & 0.0283 & 0.1567 & Severe disorders of development \\
2015 & 0.0263 & 0.1572 & Severe disorders of development \\
2020 & 0.0330 & 0.1753 & Severe disorders of development \\
\hline
\end{tabular}

According to the calculation results, the coupling coordination degree of urban spatial natural resourcesmaterial space-economic society and society in the complex giant system of Badong County has maintained the type of development of "severe imbalance" since 2010-2020, and the coupling coordination degree has achieved extremely slight growth from 2010 to 2015, with a growth rate of $0.32 \%$, and the coupling coordination degree has reached a certain degree of growth from 2015 to 2020 , with a growth rate of $11.51 \%$. Results Analysis: Although the regional coupling coordination is showing an increasing trend, the degree 
of coordinated development between the three systems of natural resources, material space, economy and society is still in the stage of dissonance, and the intensity of the imbalance is greater. In addition, by combining the results of coupling degree and coupling coordination settlement in the study area, it further shows that the interaction between the spatial natural resources-material space-economic and social complex giant system in Badong County is strong, but the relationship of action is still in the stage of coercion constraint, based on the time trend of coupling coordination degree, the current development shows a unified upward trend, and the future is moving towards the direction of high development and coordinated development.

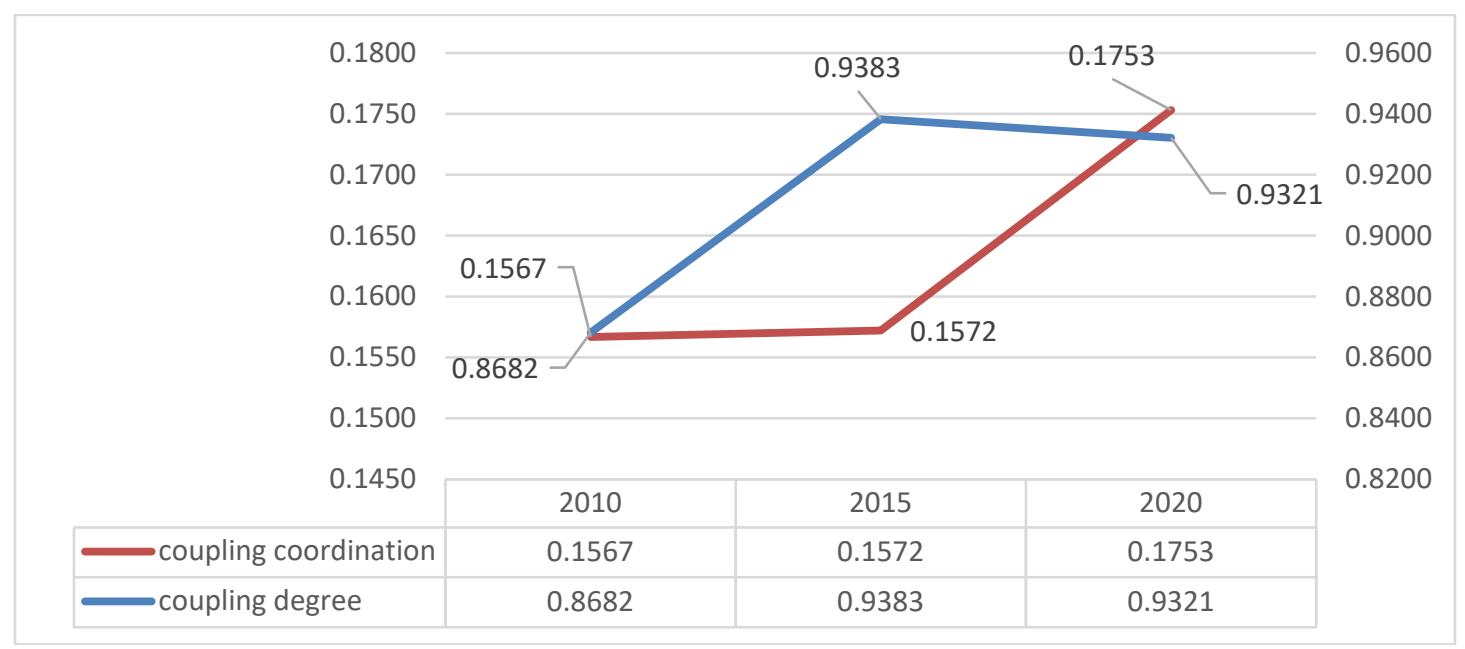

Fig.4 The evolution trend of coupling coordination degree in Badong County

\section{Conclusion}

Based on the qualitative analysis of the general situation of natural resources-material space-economic society and society in Badong County, combined with the coupling coordination model, this paper evaluates the trend of the coordinated evolution of complex giant system coupling in Badong County in 2010, 2015 and 2020. However, the level of coupling coordination is only in the serious imbalance development type, that is: Badong County natural resources - material space - economic and social systems are in the low-level coupling of the constraint stage.

In the future development should: 1, regular geological disaster risk assessment. To identify hidden danger points for major geological hazards, to provide a basis for the construction of a geological hazard investigation and evaluation system, rational development and utilization of the geological environment, the implementation of geological hazard monitoring and early warning and prevention projects, and to provide support for local government decisionmaking management and the prevention and control of geological disasters in related fields. 2, speed up the water pollution control and waste treatment facilities construction. According to the current situation and demand of sewage and garbage treatment facilities in Badong County, on the basis of strengthening the operation and supervision of domestic sewage and garbage treatment facilities in Badong County and market towns, plans and construction of sewage, waste treatment facilities and supporting facilities for townships lacking sewage, garbage centralized treatment facilities, large population and large amount of pollution.
3 , adhere to the ecological environment protection line. We will strengthen the monitoring and evaluation of ecological environment quality and ecosystem function in the Red Line area to ensure the stability and improvement of the ecological environment quality in the Red Line area. 4, the framework is more complete public service facilities system. Form a reasonable structure, balanced development, sound network, highquality service, covering the county's relatively complete public cultural service system. 5. Speed up the construction of circular economy and the reform of industrial structure. We will increase the proportion of three productions and promote the prosperity of the green economy.

\section{Acknowledgments}

1. National Natural Science Foundation of ChinaResearch on Multidimensional Coupling Enhancement of the Resilience of the "City-Rural" Space Complex Giant System in the Three Gorges

Reservoir Area ( 5207082902)

2. Scientific Research Fund of Hubei University of Technology_-Research on Multidimensional Coupling Enhancement of the vulnerability of the "CityRural" Space Complex Giant System in the Three Gorges Reservoir Area（BSQD2020047

\section{References}

1. Xiong Jianxin,Chen Duanlv,Peng Baofa,Deng Suting,Xie Xuemei. Spatio-temporal Difference of Coupling Coordinative Degree of Ecological Carrying Capacity in the Dongting Lake Region [J]. Scientia Geographica Sinica,2014,34(09):1108-1116. 
2. Zhu Lijiang,Li Zilian. Coupling Coordination Development of Industry-Population-Spacein City Cluster of Yangtze River-Delta Region [J]. China Population, Resources Environment,2015,25(02):75-82.

3. Zeng $\mathrm{R}$ ong, Wei Yiming, Fan Ying, et al. Analysis and Assessment Indicator System for Harmonization Development amongPopulaition , Resource , Environment and Economy [J] . ChineseJournal of Management Science, 2009, ( S1) : 310-317.

4. Earth System Sciences Committee, NASA Advisory Council.Earth system science -A closer view[R]. Washington DC: NASA, 1988.

5. Crutzen P, Stoermer E. The Anthropocene'[J]. IGBP Newsletter, 2000, 41: 17-18.

6. Liu Yansui. Modern human-earth relationship and human-earth system science. Scientia Geographica Sinica,2020,40(8):1221-1234.

7. Deng Wei,Zhang Shaorao,Zhang Hao,Peng Li,Liu Ying.Transitional geospace from the perspective of human-nature coupling: Concept, connotations, attributes, and the research framework[J]. Geographical Research,2020,39(04):761-771.

8. Fang Chuanglin,Zhou Chenghu,Gu Chaolin,Chen Liding,Li Shuangcheng. Theoretical analysis of interactive coupled effects between urbanization and eco-environment in mega-urban agglomerations [J]. Acta Geographica Sinica,2016,71(04):531-550.

9. Cui Muhua. The Relationship of Coupling Coordination between Urbanization and Ecological Environment-A Case of Urban Cluster in the Central Geography,2015,35(07):72-78. Plains[J].Economic

10. Wang Qi,Tang Fanghua. The Evaluation of Coulpling Coordination Development of EcologyEconomy Society System in Dongting Lake Area [J]. Economic Geography,2015,35(12):161-167+202.

11. Yang Shiqi,Gao Wangsheng,Sui Peng,Chen Yuanquan,Xu Cui. Evaluation of the Harmony Degree of Ziyang District's Ecologic-EconomicSocial System [J]. China Population, Resources and Environment,2005(05):71-74.

12. Li Guiyuan,Yang Fanxing,Cheng Liyuan,Ling Zhichang. Research on Dynamic Change of Natural Capital and Ecological Function of Three Gorges Reservoir Area [J]. Resource Development \&. Market,2016,32(11):1323-1328+1410.

13. Li Guiyuan. The Study on Multidimensional Coupling Relationship of City Space of the Three Gorges Reservoir [D].Wuhan University,2015.

14. Li Guiyuan, Liu Di, Ling Zhichang. An Empirical Study on Rural Planning Under the Background of Multi-regulation: Taking Chexi Village of Yichang City as an Example [J]. Huazhong Architecture,2018,36(10):95-100. 